Journal of Economics, Finance and Accounting Studies (JEFAS)

ISSN: 2709-0809

DOI: 10.32996/jefas

Journal Homepage: www.al-kindipublisher.com/index.php/jefas

\title{
Economic Growth at the Expense of Environmental Degradation: Evidence from the Philippines
}

\author{
Coleen Joyce De Robles ${ }^{1} \square$ Jose Rafael De Leon ${ }^{2}$ and Carlos Manapat ${ }^{3}$ \\ ${ }^{12}$ Department of Economics, Faculty of Arts and Letters, University of Santo Tomas, Manila, Philippines \\ ${ }^{3}$ Associate Professor, Department of Economics, Faculty of Arts and Letters, University of Santo Tomas, Manila, Philippines
}

$\square$ Corresponding Author: Coleen Joyce De Robles, E-mail: coleenmderobles@gmail.com

\begin{tabular}{ll}
\hline ARTICLE INFORMATION ABSTRACT \\
\hline
\end{tabular}

Received: 11 October 2021

Accepted: 26 November 2021

Published: 31 December 2021

DOI: 10.32996/jefas.2021.3.2.25

\section{KEYWORDS}

CO2 Emissions, Environmental Kuznets Curve, Pollution Haven Hypothesis, Philippines, Economic Growth, Foreign Direct Investment, Urbanization
This study presents an empirical analysis of three macroeconomic variables, namely, Gross Domestic Product, Foreign Direct Investment, and Urban Population and their relationship with the emissions of $\mathrm{CO} 2$ in the Philippines from the period of 1970 to 2018. The researchers used OLS multiple linear regression in analyzing their data. The results reveal that Gross Domestic Product and Foreign Direct Investments exhibit a statistically significant relationship with $\mathrm{CO} 2$ emissions. The findings of this study suggest that the Philippines' reliance on high-polluting industries as drivers of economic growth will only worsen its environmental quality. Moreover, its weak environmental laws provide foreign investors with the opportunity to exploit the environment in exchange for FDI inflows to the country. Furthermore, the results of this study support the scale effect in the Environmental Kuznets Curve hypothesis, as well as the Pollution Haven Hypothesis.

\section{Introduction}

Climate change has become more evident in recent years. The Philippines, in particular, have suffered the consequences of global warming. Several studies suggest that economic growth might have a role in worsening the quality of the environment. This necessitates the need to identify the determinants of climate change in order to develop intergovernmental policies that aim to slow down environmental degradation before we experience its irreversible effects.

\subsection{Background of the Study}

A. Carbon Dioxide (CO2) Emissions

The increasing quantity of $\mathrm{CO} 2$ emissions produced by the burning of fossil fuels is widely believed to add to the greenhouse effect and lead to global warming (Buenavista \& Palanca-Tan, 2021), which causes climate change. This poses an urgent environmental issue, especially since the $\mathrm{CO} 2$ emissions in the Philippines are still growing today (Fig. 1).

Copyright: (c) 2021 the Author(s). This article is an open access article distributed under the terms and conditions of the Creative Commons Attribution (CC-BY) 4.0 license (https://creativecommons.org/licenses/by/4.0/). Published by Al-Kindi Centre for Research and Development, London, United Kingdom. 
Carbon Dioxide (CO2) Emissions in the Philippines (1970-2018)

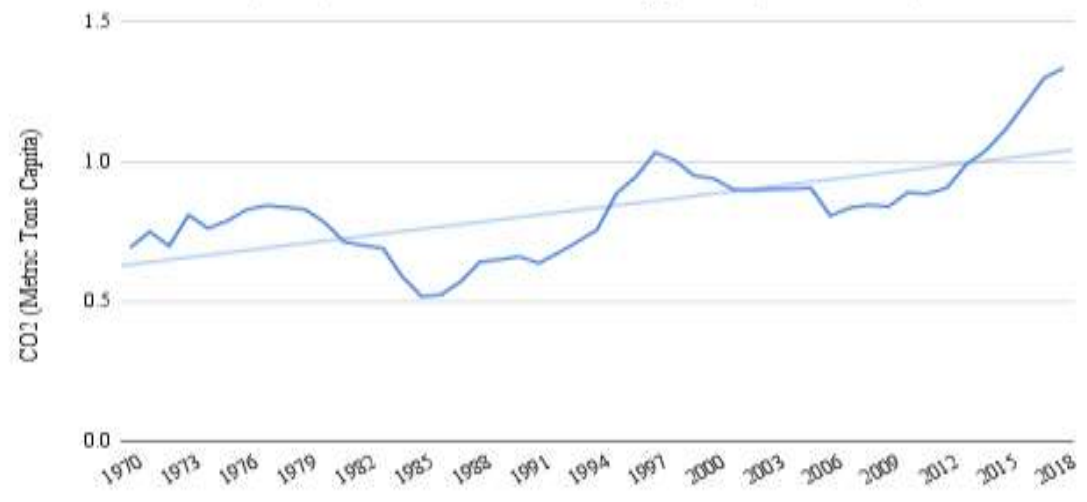

Figure 1. CO2 Emissions in the Philippines (1970-2018)

The IPCC or the Intergovernmental Panel on Climate Change attributed global warming to the increase in human activities in the past 50 years, and that because of this, $\mathrm{CO} 2$ emission is expected to exponentially rise in the future (PAGASA, n.d.). It is evident that the Philippines has suffered from climate change, and it is most felt in the temperature changes and the patterns of rainfall, which only makes the country more vulnerable and prone to natural disasters than it already is.

\section{B. Sources of $\mathrm{CO} 2$ Emissions in the Philippines}

The sources of $\mathrm{CO} 2$ emissions vary in every country. However, it is generally accepted that these are caused by increased human activities, such as the production of commodities, the expansion of industries, as well as urban population growth (Cederborg $\&$ Snöbohm, 2016). One of the Philippines' top sources of CO2 emissions is the energy sector (Climate Transparency, 2020). It makes sense as production, industries, transportation, technologies, and even mobilization require energy to work. The downside to this is the amount of CO2 the Philippine energy sector generates. The Department of Energy (2020) reported that in 2015, the country's primary energy mix was dominated by fossil fuels, which is known to produce high levels of carbon emissions. Meanwhile, the transportation and the industry sectors had the biggest share of final energy consumption in the Philippines. With that, the Philippines is estimated to produce 444.5 million tons of carbon emissions in 2040 (Department of Energy, 2020). Despite seeing the energy sector's role in boosting economic growth, it is worth considering the costs of the economic gains from these activities and if it is worth endangering the future of mankind.

\section{a. Economic Growth}

Economic growth is typically measured by the sustained increases in Gross Domestic Product or GDP for a long period (O'Sullivan et al., 2012). This measures the total output produced by the economy in a period of time. Other factors such as a country's standard of living and its environmental welfare are not included in the computation of economic growth. In measuring economic growth, economists use the real GDP as it measures the total output without adjusting for inflation. This is reflected in Figure 2, wherein the GDP (in constant USD) is seen to be increasing throughout the years.

Gross Domestic Product (GDP) in the Philippines (1970-2018)

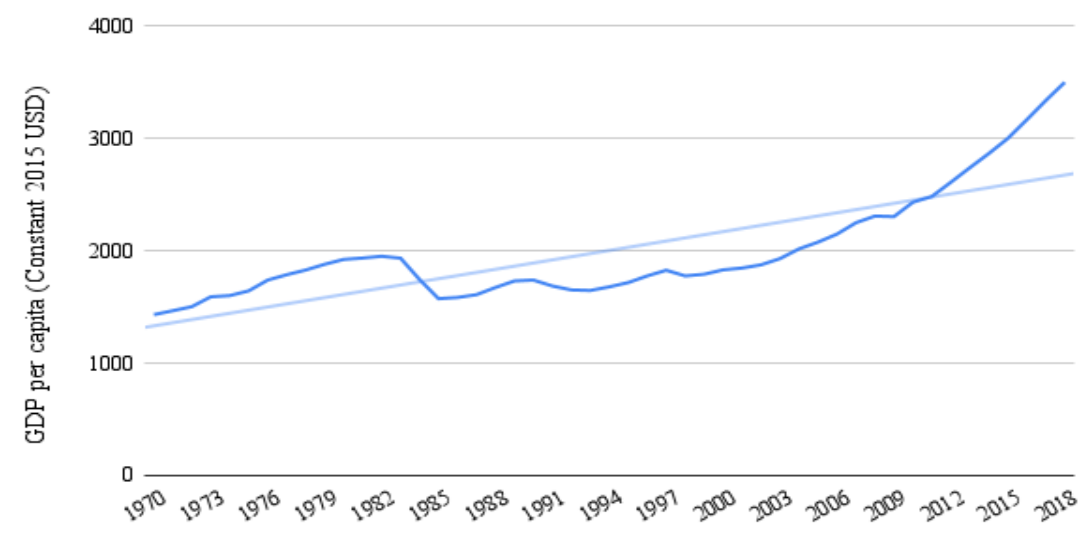

Figure 2. Gross Domestic Product per capita in the Philippines (1970-2018) 
The Philippines had a full-year growth rate of $6.2 \%$ in 2018 , which was mainly driven by the construction industries, trade and repair of motor vehicles, and other services (Philippine Statistics Authority, 2019). Meanwhile, in 2015, the manufacturing industry had a share of $23.25 \%$ of the Philippines GDP, which gave 3.2 million Filipinos jobs (Philippine Board of Investments, 2017). These drivers of growth primarily consume fossil fuels for their energy consumption, which are not beneficial to the country's CO2 emission reduction. It cannot be denied that energy consumption in the different sectors of the economy contributes to carbon emissions, even more so that the Philippines' dependence on renewable energy is still not being strengthened today. According to the Climate Transparency Report (2020), the Philippines energy-related carbon emission by sectors in 2018 are as follows: $51 \%$ comes from the power sector; $26 \%$ from the transportation sector; $13 \%$ from the industrial sector; $7 \%$ from the building sector; and $1 \%$ and $2 \%$ respectively for the agriculture sector and other sectors of the economy. The reliance of the Philippines on fossil fuel energy, the dominant primary energy in the country, is already profoundly rooted for an overnight shift to renewable energy resources to dominate the energy mix. Moreover, the Philippines does not have sufficient policies to reduce CO2 emissions (Ibanez et al., 2019). This shows that the Philippines is currently facing a dilemma between its focus on growing its economy and reducing its dependence on fossil fuels to curb $\mathrm{CO} 2$ emissions. According to the Ayala Corporation Chief Financial Officer and Chief Sustainability Officer, TG Limcaoco (Fernandez, 2021), the acknowledgement of trade-off between the economic reality and economic goals must be realized.

\section{b. Foreign Direct Investment}

The Philippines have been attracting Foreign Direct Investment or FDI since the 1950s when import-substituting FDI began in the country. However, Figure 3 shows the instability of the FDI climate due to different factors that have transpired throughout the history of the Philippines and of the world. Some of these factors are oil price shocks (1975), recession (1980), political climate changes from Marcos administration to Aquino administration (1980-1988), Philippine coup d'état attempt (1989), among many others (Mercado-Aldaba, 1994). However, despite the volatility of the investment climate in the country, Figure 3 depicts an upward trend in the FDI inflows from 1970-2018.

\section{Foreign Direct Investments (FDI) in the Philippines (1970-2018)}

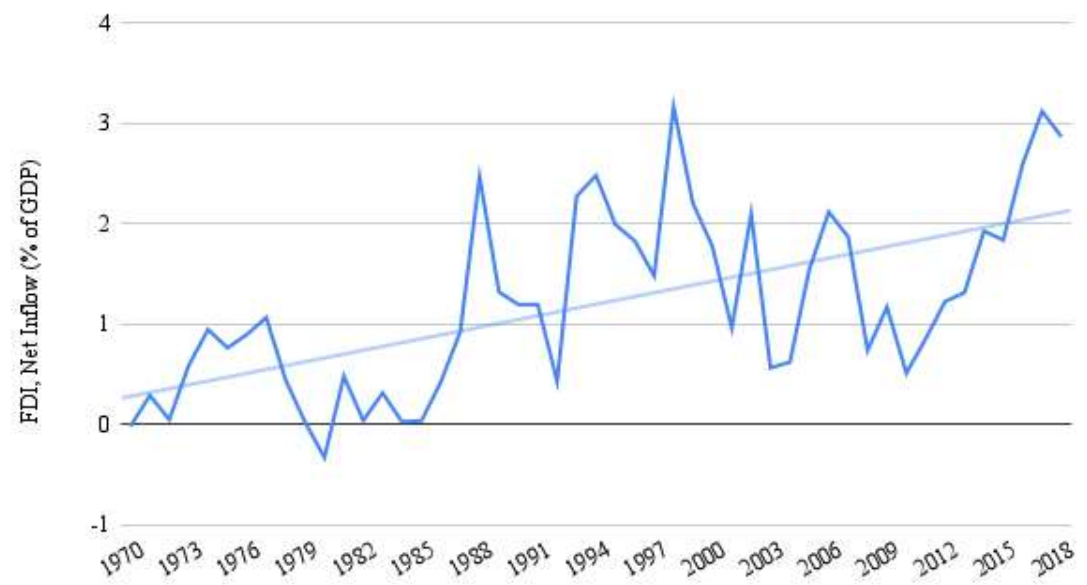

Figure 3. FDI in the Philippines (1970-2018)

Mercado-Aldaba (1994) reassessed the FDI in the Philippines from the 1950s to 1993 and found that the country's FDIs are mostly concentrated in the manufacturing sectors, particularly the chemical industries, food processing industries, petroleum, coal industries, transportation equipment, and machinery and appliance manufacturing industries (Mercado-Aldaba, 1994). On another note, in the 1990s, three of the ASEAN-four, consisting of Singapore, Malaysia, and Indonesia, experienced growth in their FDI, while the Philippines lagged. However, the Philippines benefited from this as these countries' labour costs grew, causing foreign investors to relocate their labour-intensive industries to the country (Austria, 1998). This was due to the Philippines offering a skilled and cheap labour force which made its investment climate during the 1990s reasonably attractive to foreign investors.

Of all the industries in the Philippines, the manufacturing sector remained to be the most concentrated among all of them until 2018. According to the foreign investment report of the Philippine Statistics Authority, the manufacturing industry received the largest share of foreign investments in 2018, amounting or Php 85.1 billion, while the electricity, gas, steam, and air conditioning supplies came in second with Php 30 billion (Philippine Statistics Authority, 2018). In 2017, SEC Ramon Lopez of the Department of Trade and Industry described the manufacturing industry to be capable of producing investments as well as well-paying jobs for Filipino workers. Thus they decided to further boost this industry (Department of Trade and Industry, 2018). 


\section{c. Urbanization}

One of the driving factors of economic growth in the Philippines is urbanization. However, it is important to note that urbanisation contributes to the growth of the total output of an economy; it also contributes to $\mathrm{CO} 2$ emissions. Moreover, urbanization also poses various challenges to a country, such as vulnerability to climate change, capacity gaps in cities, outdated urban development policies, as well as inadequate financial capacities of cities and municipalities (UN Habitat, 2015).

Urbanization in the Philippines (1970-2018)

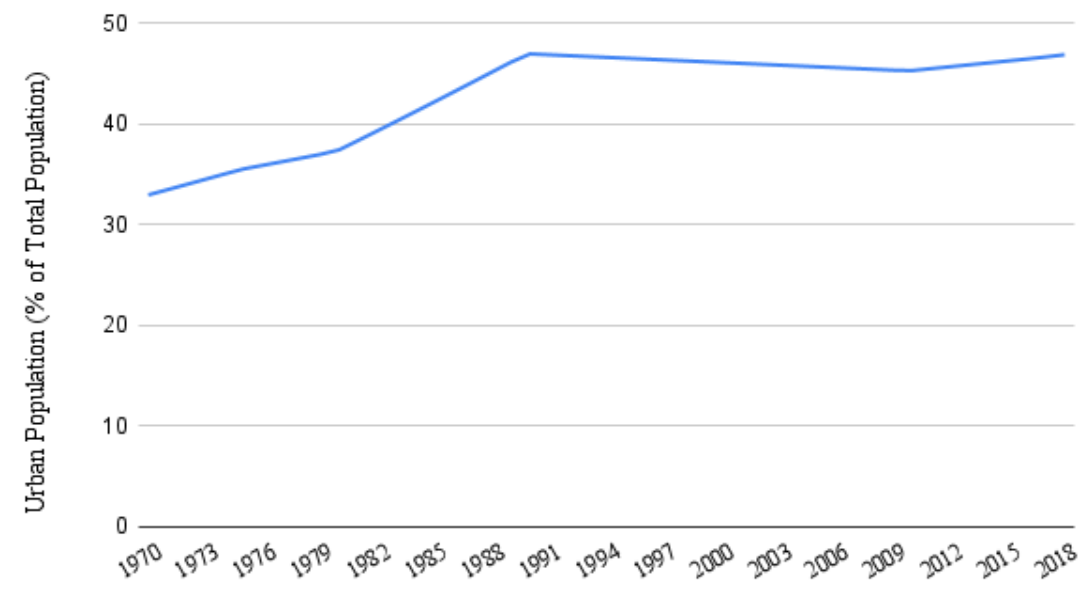

Figure 4. Urban Population in the Philippines (1970-2018)

According to the 2015 Census of Population, the Philippines had a record of $51.2 \%$ of the level of urbanization, which reflects a total of 51.73 million Filipinos residing in urban-classified barangays (Philippine Statistics Authority, 2019) and that this is to be doubled in number in 2050 (World Bank, 2017). The majority of a country's economic activities are concentrated in its cities, where jobs, services, and other opportunities are to be found. This brings positive impacts to economic growth as it increases its productivity. Much of the Philippines' population works in the service sector, amounting to $55.9 \%$ of the total employed persons in 2018 , while $18.1 \%$ worked in the industry sector and $26 \%$ in the agriculture sector (Philippine Statistics Authority, 2019).

In 2017, the Philippines ranked second-highest average urban density in the East Asia and Pacific region, leading to congestion, land scarcity, lack of basic services and housing, and increasing pollution, natural hazard, and commuting costs. Moreover, the slum population in urban areas is growing as pressures on housing and basic services demands have increased due to the high rates of migration to the major cities in the country. This results in informal settlements commonly situated along the shorelines, exposing them to natural and other hazards. If left unmanaged, the Philippines will continue to risk exposing its environment to the growing levels of pollution (World Bank, 2017). It will also continue to risk its people's welfare and security.

\section{Consequences of $\mathrm{CO} 2$ Emissions in the Philippines}

One of the consequences of the rapidly increasing $\mathrm{CO} 2$ emissions in the Philippines is high temperatures and abundant rainfall. The Philippines is already vulnerable to natural disasters such as typhoons, droughts, floods, and heatwaves (Rincón and Virtucio, 2008) due to its geographical location, lying in the Pacific Ring of Fire. Therefore, further exposing the country to the impact of $\mathrm{CO} 2$ emissions only intensifies its vulnerability and risks towards the weather disturbances brought about by climate change. The IPCC forecasted that the temperature and precipitation of the earth will accelerate in the following decades, that the occurrence of extreme weather events such as heatwaves and hot extremes will be higher, and the sea levels will significantly rise, affecting $70 \%$ of the provinces in the country that are dependent on the resources near the coastal zones (Rincón and Virtucio, 2008).

To demonstrate one of the consequences of climate change in the Philippines, the most destructive typhoon that hit the Philippines was Yolanda's typhoon in 2013. Not only did this typhoon destroy buildings, flooded roadways, and isolated communication lines, typhoon Yolanda also claimed thousands of lives (Carlowicz, 2013; Mersereau, 2013). As a result, Greenpeace Southeast Asia forwarded a petition to the Commission on Human Rights of the Philippines (CHRP), presuming that human rights are affected by the intensity of climate change. The petition asks the commission to investigate whether the major carbon companies (oil, natural gas, coal, and cement, non-state companies) in the Philippines contribute considerable damages to the Filipinos. The CHR agreed to look into this case, making it the first conducted investigation wherein climate change was framed to be violating human rights (CHRP, 2018). The testimonies released in the court proceedings revealed that climate change not only affects the environment, 
per se. It also affects people--it goes beyond the environmental problems as it also inflicts socio-economic issues. For instance, a certain Arthur Golong released his testimony wherein he described how typhoon Yolanda, climate change, caused him to lose his salon, his home and how it gave him anxiety attacks (National Inquiry On Climate Change, 2018). This underlines the importance that the Philippines should pay a great deal of attention to climate change, most especially on how it can adapt and curb the adverse effects this brings.

\subsection{Statement of the Problem}

Humanity is already experiencing the detrimental effects of climate change, and it will likely intensify significantly over time unless $\mathrm{CO} 2$ emissions are lessened. This imposes the need to identify which economic variables have a statistically significant relationship with carbon emissions in the country, as it has not been researched extensively in the country. The researchers of this study acknowledged the importance of establishing the possible link between environmental degradation and economic growth, especially so in the Philippine setting. Through this paper, the researchers aim.

1. To determine whether any of the following macroeconomic factors have a statistically significant impact on Carbon Dioxide emissions:

a. Gross Domestic Product (GDP)

b. Foreign Direct Investment (FDI)

c. Urbanization (URBAN)

\subsection{Formulation of Hypothesis}

Based on the problem statement, the research hypothesis was formulated and tested at the significance level of 0.05 . The researchers of this study formulated the following hypotheses:

Hypothesis 1:

H1: Gross Domestic Product does not cause an increase in Carbon Dioxide emissions in the Philippines.

H2: Gross Domestic Product causes an increase in Carbon Dioxide emissions in the Philippines.

\section{Hypothesis 2:}

H3: Foreign Direct Investments does not cause an increase in Carbon Dioxide emissions in the Philippines.

H4: Foreign Direct Investments cause an increase in Carbon Dioxide emissions in the Philippines.

\section{Hypothesis 3:}

H5: Urbanization does not cause an increase in Carbon Dioxide emissions in the Philippines.

H6: Urbanization causes an increase in Carbon Dioxide emissions in the Philippines.

\subsection{Scope and Limitations}

The scope of this study involves the carbon dioxide emissions, gross domestic product, foreign direct investment, and urban population growth of the Philippines from 1970 to 2018. The data gathered for this study are in annual values, as the researchers could not find other data. The researchers of this study were able to gather 49 years' worth of data as the observations used for the empirical analysis for this paper. The researchers used the ordinary least squares (OLS) method and will only base their analyses and conclusions on their model results after undergoing the necessary statistical treatments.

Energy usage plays an important role in economic growth as well as climate change. However, due to data unavailability, the researchers did not include this variable as the latest year for the energy use dataset from the World Bank Economic Indicators was in 2014. Moreover, the Department of Energy only provides data from 2003 to 2020 in accordance with the enactment of the Electric Power Industry Reform Act in 2001; any data prior to 2003 was unavailable.

As for testing the model of the Environmental Kuznets Curve hypothesis, the researchers opted not to compute for the threshold point in this hypothesis as they were only concerned with determining the relationship of their selected variables with $\mathrm{CO} 2$ emissions, not validating the EKC model.

\subsection{Significance of the Study}

The purpose of this paper is to contribute to existing related literature on the impacts of economic growth, foreign direct investments, and urbanization on carbon emissions with an empirical approach that tests whether or not these macroeconomic factors contribute to climate change. This study is not expected to significantly influence Filipino policymakers' economic and 
environmental strategy. However, if the results of this study intrigued future researchers and policymakers, further examination may be performed. Furthermore, the researchers conducted this study to benefit the following:

- Future Researchers. Future researchers on this topic may use this research paper to aid and be used as a reference for a similar prospective study.

- Environmental Economists/Researchers. This paper should provide empirical evidence on the relationships between three macroeconomic indicators and the increasing carbon emissions of the Philippines. The findings of this study may aid researchers in the field of environmental economics with their studies.

- Policy and Regulatory Institutions for Development Planners. This research paper may be used as a reference for policymakers on their decision-making and authoring sound policy choices on both economic and environmental strategies for the Philippines. This paper may benefit the following institutions:

0 Department of Science and Technology (DOST)

National Economic and Development Authority (NEDA)

Department of Trade and Industry (DTI)

The Department of Human Settlements and Urban Development (DHSUD)

- National Commission on Human Rights. In line with the National Commission on Human Rights project, the National Inquiry On Climate Change (NICC), this study may contribute empirical evidence to strengthen the environmental protection policies that the CHR may recommend to policymakers.

\section{Review of Related Literature}

\subsubsection{Environment vs Economic Growth}

A tool formulated by Grossman and Krueger measures the relationship between economic growth and carbon emissions, wherein the level of carbon emission is expected to rise as the economy grows until it reaches a turning point. Beyond that turning point, the economy grows while the carbon emitted will decline. This results in an inverted U-shaped curve called the Environmental Kuznets Curve. Majority of the studies that the authors found for this literature review test the EKC hypothesis. The researchers of this study reviewed literature that provides evidence that GDP and CO2 emissions have a relationship.

Buenavista and Palanca-Tan (2021) investigated the effects of GDP, Trade, and FDI on carbon emissions in the ASEAN. GDP was used to support the claim that income growth has an effect on the economic activities of a country; Trade was used to support the claim that it mobilizes the transport sector of the economy, contributing to increased energy use and CO2 emissions; FDI was used to demonstrate that foreign investors promote "dirty industries" in countries with lenient environmental policies. The findings of this study show how the EKC is applicable to the ASEAN from the period of 1970 to 2011. The authors made use of pooled OLS regression but later re-estimated using the panel corrected standard errors method to remedy heteroskedasticity and multicollinearity of their data set. Their findings found that GDP contributes to the rise of CO2 levels in the ASEAN, while trade and FDI do not. This validates the EKC theory and refutes the pollution haven hypothesis. Moreover, it has been found that it would take years for most ASEAN members to reach the peak of the EKC, thus necessitating the need for strict economic strategies focused on combating the rise of carbon emissions. This is due to the estimated income threshold (carbon emissions will decrease alongside economic growth), which is still too high for some ASEAN members to achieve.

Adu and Denkyirah (2017) analyzed the relationship between economic growth and the rise of carbon emissions and CoWaste to validate the existence of EKC. After testing selected West African countries, they found that economic growth significantly increases the $\mathrm{CO} 2$ levels and CoWaste only in the short-run, garnering no effects in the long run. It was realized that environmental pollution does not decrease even as income levels continue to go up. Similarly, a study conducted by Beyene and Kotosz (2020), wherein they investigated 12 East African countries to see if they validate the existence of EKC, yielded the same conclusion. They tested their hypothesis with the variables: GDP per capita, globalization, FDI, and population growth. The EKC in the 12 East African countries demonstrated a bell curve in the long run, not an inverted U-shape curve. The authors suggest producing policies that would protect these East African countries from the adverse effects of carbon emissions in the long run through improving technologies and modernization of industries.

Rani and Kumar (2019) also investigated the EKC hypothesis in India and China using the autoregressive distributed lag model (ARDL) approach. The findings in their study showed that the EKC hypothesis is valid in both the short-run and long-run income elasticities in both countries. Their findings showed that their variables, GDP, energy consumption, and population growth, all have a short-run and long-run, positive and significant effect on the CO2 levels in India and China. In line with the previously mentioned studies, both India and China will face environmental degradation in the coming years to reach the peak of the EKC, where environmental recovery can happen. 
The Belt and Road group of countries and the Organization for Economic Co-operation and Development countries were tested by Sun et al. (2020) for EKC from 1992 to 2015. In estimating the increase of carbon emissions, the authors tested economic growth, trade openness, energy consumption, and urbanization as contributing variables. As a result, they found that an increase in these macroeconomic indicators also causes an increase in carbon emissions. The authors explained how economic growth calls for an increase in energy consumption which emits $\mathrm{CO} 2$ to the atmosphere. Upon reaching the threshold point, economic growth is found to reduce carbon emissions. It is also found that trade openness enables environmental degradation as it contributes to air pollution due to the increased consumption of technologies. On the same note, urbanization was also found to increase carbon emissions as urban population growth demands more energy consumption.

Other studies that are related to the nexus between $\mathrm{CO} 2$ and economic growth tested income inequality with carbon emissions by utilizing the Gini coefficient. A study by Kusumawardani and Dewi (2020) tested the impact of the Gini coefficient, GDP per capita, urbanization, and the Indonesian age-to-population growth on carbon emissions in Indonesia in the period of 1975 to 2017. Their results show that income inequality increases the emission of CO2. More importantly, the study found that GDP and CO2 show that EKC is valid in Indonesia, resulting in an inverted U-shaped curve. Another study conducted by Q. Liu et al. (2019) tested the EKC in China from 1996 to 2014 and found that an increase in income results in an increase in carbon emissions. Similar to Kusumawardani and Dewi (2020), the problem of the increasing income inequality in China also worsens their environmental quality. Additionally, their empirical results also present the inverted U-shaped curve between CO2 and GDP in the EKC hypothesis. Meanwhile, the authors also tested urbanization with carbon emissions and found that there is no significant relationship between the two variables. With that, the authors emphasize that China should focus on achieving a "Low carbon economy" in the next following years to reduce the intensity of environmental degradation.

In some cases, errors arise in the econometric models testing the EKC hypothesis. Particularly, the study conducted by Månsson et al. (2018) estimated the EKC while multicollinearity is present. The authors initially estimated their model using the Dynamic Ordinary Least Squares (DOLS) method, which added lagged variables to remedy multicollinearity. Their findings showed how DOLS is surpassed by their new method, Ridge DOLS. In contrast, DOLS overestimates the effect of GDP on CO2, the Ridge DOLS. The Ridge DOLS produces a lower mean squared error (MSE) compared to DOLS, which means the results are more accurate than just sticking to the traditional estimation method. The authors noted that despite DOLS remedies bias and other errors in a model, the problem of multicollinearity is not usually resolved and still contributes to higher MSE. Finally, the authors acknowledged that studies on EKC that use the DOLS method are recommended to apply the Ridge DOLS method to decrease the degrees of collinearity.

Some studies tested the grounds of the EKC, asking whether or not it actually exists in most countries. For instance, a study by Maneejuk et al. (2020) found that EKC is only valid in 9 out of 44 countries that they tested. The authors regressed GDP, financial development, urbanization, and the industrial sector of these countries to their respective carbon emissions. Their findings show that the EKC does not hold true as most countries do not lower their carbon emissions even after sustaining economic development. In short, despite a country passing the turning point of economic growth, it does not mean a country would automatically generate less pollution.

Another study conducted by Palanca-tan et al. (2016) revealed that the EKC does not hold true in the Philippines as they have found no evidence of the inverted U-shaped curve in the relationship between carbon emissions and economic growth. However, the authors employed a second model wherein they removed GDP squared and found a positive linear relationship between GDP and $\mathrm{CO} 2$ emissions in the Philippines in both the short and long run. This finding provides evidence that economic growth in the Philippines contributes to carbon emissions and that stricter environmental constraints must be subjected to the country's economic growth policies. Moreover, the authors have found significant relationships between $\mathrm{CO} 2$ and the macroeconomic variables, which are FDI and urbanization. Their findings show that the Philippines observe the pollution haven hypothesis, wherein $\mathrm{CO} 2$ levels intensify because of the growth of the manufacturing sector that is supported by the inflow of FDI. On the other hand, urbanization is found to have a negative elasticity impact on carbon emissions, which is in contrast to what the authors predicted. Since the Philippines belongs to the lower-middle-income countries, Palanca-Tan et al. predicted urbanization to have a positive elasticity to CO2 due to the lack of cleaner technology that allows a greener source of energy intensity. However, the authors attributed this negative elasticity to the Philippines' high employment rates similar to that of high-income countries. Moreover, it was shown that more than $50 \%$ of Filipinos work in the services sector as compared to the manufacturing sector, which generates more carbon emissions.

\subsubsection{Environment vs Urbanization}

Some researchers used urbanization as a determinant of carbon emissions. Urbanization is often described as either urban economic growth or urban population growth. Urban economic growth accounts for growth in urbanized areas due to industry advancements which cause the emission of $\mathrm{CO} 2$. Meanwhile, urban population growth accounts for the migration of population 
to urbanized areas. In contrast to the study of Palanca-Tan et al. (2016), several studies show that urbanization increases the emission of $\mathrm{CO} 2$.

In the study of S. Zhang et al. (2021), the authors tested the carbon emissions of the construction industry to gauge their impact on China's environmental degradation. It is hypothesized that as China becomes more urbanized, cleaner production from industries is implemented, which in turn decreases carbon emissions. However, it is important to note that the results for the relationship between urbanization and carbon emissions vary in different areas in China. Some local Chinese governments struggle with achieving urban population growth, thus resulting in heterogeneous data for the different regions. To investigate this, the authors classified China into three regions: urbanized, urbanizing, and under-urbanized. With this, it was found that carbon emission intensity varied from the different regions; urbanizing regions reduced more carbon emissions than urbanized regions. Meanwhile, under-urbanized areas increase carbon emissions because these regions have lower urban population growth than urbanized and urbanizing areas, which is needed for the improvement of urban housing and structures. Furthermore, their study found that the relationship between urban economic growth in all regions and their carbon emissions validated the EKC hypothesis.

Ali et al. (2019) analyzed the impact of urban population growth on the carbon emissions in Pakistan and found that urbanization enhances the levels of carbon emissions. According to the authors, about $50 \%$ of Pakistan's population has already migrated to urban areas for employment opportunities, health and education services, landholding, and access to major industries. It has been expressed that because of industrialization, urbanization deteriorates the quality of the environment. Moreover, vehicle emissions from private transports contribute greatly to the increase of carbon emissions in Pakistan because people are more willing to use private vehicles rather than Pakistan's "bleak" public transportation system. Aside from Pakistan, a study conducted in India also shows the same conclusion, particularly on how carbon emissions from road transportation worsen urban areas' environments. However, Ahmed et al. (2020) explained that it is only in the short run that urbanization increases carbon emissions because transport demand is bound to increase during these stages. Nonetheless, the pollution reduction will begin as soon as urban areas start to promote energy-efficient means of transportation. This study shows the gap in Ali et al. (2019) as it provides evidence that urban transportation is not absolutely detrimental to the environment. Ahmed et al. (2020) highlight that while it is accepted that transport carbon emissions contribute to environmental deterioration, it is not necessarily applicable in the long run. That is if economies implement policies that aim to curb $\mathrm{CO} 2$, as well as aims to promote sustainability.

In some studies, it was concluded that the intensity of carbon emissions is also attributed to how resource-rich a country is. Resource-rich countries enable human activities that utilize polluting machinery in harvesting natural resources. A study by Mignamissi and Djeufack (2021) confirms this by analyzing the effect of urbanization on carbon emissions in 48 African countries. The authors found that countries with high levels of natural resources tend to be more polluting than those that are not. It is assumed that these countries have the income and the capacity to produce more goods, while resource-rich countries do not. Regardless of being rich or poor in resources, it is generally accepted that urbanization manifests high levels of pollution. Ahmed et al. (2020) also concluded that urbanization in China contributes to the increase of their carbon emissions. Their findings introduced a new perspective on urbanization, showing that the environment is compromised due to the interaction between urbanization and natural resources abundance. Their study explained that urbanization prompts an increase in the demand for natural resources, which will later be used in production. The extraction of natural resources alone contributes to pollution, even more so in the production of commodities and other economic activities following that. On a different note, it has also been found that the interaction between urbanization and human capital decreases environmental degradation. Urbanization aids the growth of educational attainment, which is deemed necessary in sustainably extracting natural resources as it requires educated and skilled workers. This is particularly important in curbing environmental degradation as it can be assumed that with higher human capital, technologies tend to be more sustainable and less detrimental to the environment.

Q. Wang et al. (2021) attempted to redefine EKC with urbanization as their primary subject. Their study solidified the EKC hypothesis by providing empirical evidence that urbanization is the threshold variable responsible for the positive correlation between GDP and $\mathrm{CO} 2$ emissions in 134 countries. This means, as a country becomes more urbanized, the more its environmental pressure increases. This is due to the expansion of economic scales, which contributes to excessive energy consumption. Energy consumption is essential in economic growth as industries increasingly demand as they grow bigger in size and in number. Moreover, the authors conclude how industry and service industries development does not help reduce carbon emissions. This is in contrast with Palanca-Tan et al. (2016), wherein it was found that urbanization hurts carbon emissions in the Philippines because of its increase in employment in the service sector.

Correspondingly, Q. Xu et al. (2018) analyzed the influence of urbanization on carbon emissions in the Pearl River Delta region from 1990 to 2014. The most evident factors affecting carbon emissions were energy efficiency and the proportion of land used for construction. The authors' results showed that urbanization both displayed Kuznets curve relationships with the carbon emissions. Economic urbanization had the most significant impact on carbon emissions in the Pearl River Delta region, followed 
by land urbanization. The impact of population urbanization on carbon emissions was minimal. In another study, Tan et al. (2020) analyzed the growth pattern of economic growth, urbanization, and carbon emissions between Indonesia, Malaysia, the Philippines, Thailand, and Vietnam from 1990 to 2018. The authors' findings show that the urban population and carbon emissions per capita in these countries are increasing, putting pressure on the countries' environmental quality. Urbanization appears to have a positive impact on economic growth. Governments in these countries should focus on environmental governance while prioritizing economic growth to achieve sustainable urbanization.

Aside from Tan et al. (2020) and Palanca-Tan et al. (2016), the researchers of this study gathered some publications that involved estimating the impact of urbanization on carbon emissions in the Philippines. Ridzuan et al. (2019) found that carbon emissions worsen the environmental quality of the Philippines because of the intensive urban growth that was observed in a densely populated country. The authors attributed this to the high levels of corruption rates in the country, which weakened the development of urbanization policies that aim to address issues pertaining to environmental degradation. Conforming to this is Wang et al. (2019), who analyzed 18 APEC countries, including the Philippines, and recommended that countries should implement energy efficiency, which would encourage urban sustainability and a sustainable lifestyle among their citizens. The single country analysis in this study reveals that a unit increase in urban population would decrease carbon emissions by 1.409972 in the long run, which is in line with the results of Ahmed et al. (2020).

\subsubsection{Environment vs Foreign Direct Investment}

Several studies also linked environmental degradation to foreign direct investments (FDI). A study conducted by Bakhsh et al. (2017) analyzed the relationship between different economic variables and carbon emissions using three different channels, the scale effect (which describes the effect of FDI on Pakistan's income), composition effect (FDI causing Pakistan's economy to shift structures), and technique effect (Pakistan's adoption of technology due to FDI). Their findings validated the existence of the Pollution Haven Hypothesis in Pakistan. They found that capital stock and the labour force participation rate have positive effects on Pakistan's GDP while having negative effects on environmental pollution. On the other hand, FDI has a negative and significant impact on environmental pollution. Furthermore, capital stock and road length both have positive and significant effects on carbon emissions while having a negative effect on Pakistan's GDP. The authors have noted that while Pakistan has favoured foreign investors, they should also look out for Pakistan's environmental degradation brought by FDI. A study by Malik et al. (2020) revealed that in the period of 1971 to 2014, Pakistan also showed evidence of the pollution haven hypothesis wherein FDI intensified carbon emissions. The authors attributed the rise of carbon emissions to foreign investments in Pakistan's mining and quarrying sectors. These sectors make use of energy consumption, which in theory, destroys the environment.

Another study conducted by C. Zhang and X. Zhou (2016) tested the relationship between CO2 emissions and FDI. In contrast to the study of Bakhsh et al. (2017), this study supports the pollution halo hypothesis, which means that FDI decreases CO2 levels because of the green exports brought to China by foreign investors. In the same way, like most papers, this study underlines the importance of imposing stringent economic policies. Specifically, the authors recommend that China attract more foreign investors to further lower the carbon emissions in their country. With this, technological advancements and greener means of sourcing energy should be utilized in China in the following years.

Mahadevan and Sun (2019) tested China's outward foreign direct investment's (OFDI) effect on the carbon emissions of countries that are part of the belt and road initiative (BRI) and found empirical evidence that both the pollution haven hypothesis and pollution halo hypothesis can be observed in the countries involved. More specifically, it was found that OFDI increases the emission of carbon dioxide in lower-middle-income BRI countries while it decreases the carbon emission of those that are lowerincome countries. China's investment in technologies that do not follow environmental standards makes lower-middle-income BRI countries vulnerable to the adverse effects this brings. On the other hand, China's inward FDI (IFDI) reduced the carbon emissions in China as they started to invest in greener technologies, which meant energy-saving technologies were implemented. Similarly, the study of Rafindadi et al. (2018) conforms to the pollution halo hypothesis as they found that IFDI decreases the emission of carbon in the Gulf Cooperation Council since it influences investment in greener technologies. The authors also noted that as income increases in societies, the demand for a healthier environment also increases. Furthermore, GCC countries that were found to be using FDI to establish greener energy sources produce fewer carbon emissions due to their strict environmental policies. With that, the emphasis on the importance of stringency in policy implementation as an effort to achieve sustainability is underlined.

Still, in China, Cai et al. (2020) introduced a different approach to that of Mahadevan and Sun (2019) as they analyzed China's carbon emission intensity due to its IFDI and OFDI making use of interprovincial panel data. Resembling the reasoning in the study of Zhang et al. (2021), Cai et al. (2021) recognize that the different levels of regional economic development must be considered as their impact on carbon emissions vary. In light of this, their study yielded similar results that of Zhang et al. (2021) and Rafindadi et al. (2018), that China's IFDI results in reduced levels of carbon emissions. What is unique to their results is that they found 
empirical evidence that OFDI increases Chinese carbon emissions, which the previously mentioned studies lacked as they did not test China's OFDI, only its IFDI and the OFDI of the BRI countries. Moreover, the authors concluded that as OFDI continues to increase, it will come to the point that it decreases carbon emissions. What seems to be an explanation for this that has not been included in the authors' study is their results' conformity to the pollution haven and pollution halo hypothesis.

A study conducted by Kim (2019) discussed how FDI is said to adversely affect a country if they have no strict laws surrounding $\mathrm{CO} 2$ mitigation. Also, he emphasized how developed countries tend to have stricter regulations compared to developing countries, thus resulting in an influx of FDI. Foreign investors are more likely to invest in a country that has less strict laws that would not require them to pay high costs due to CO2 mitigation policies. Kim (2019) also touched on how developing countries offer lower costs of labour and resources to attract foreign investors, which in turn increases their carbon emissions. However, in his findings, 57 developing countries from Asia, America, and Africa resulted in unforeseen outcomes. Kim (2019) hypothesized that FDI worsens the condition of the environment in developing countries, but it was found that none of the countries confirmed his hypothesis. In fact, some developing countries were found to have no evidence of either the pollution halo or haven hypothesis. In the case of those that slightly exhibited the effects of FDI, they conformed to the pollution haven hypothesis because of their short labour costs, proximity to raw materials, as well as easy access to demand markets.

Some of the literature that included the Philippines in their analysis of the impact of economic growth and FDI was the study conducted by Chishti et al. (2021). Their findings revealed that pollution in the Philippines is worsened by the growth of GDP and FDI only in the short run. What is striking with this study is that the authors associated the attraction of terrorists to the Philippines' abundance of natural resources. This claim is unique from the studies of Mignamissi and Djeufack (2021) and Ahmed et al. (2020) since their studies did not consider terrorism as a variable to explain carbon emissions. There is statistically significant evidence that terrorism in the Philippines contributes to carbon emissions in both the short run and long run. The authors justify terrorism's contribution to environmental degradation to its increased energy consumption for armaments, machinery (including those that were used in the production of tanks, ammunition, and weapons), as well as cooking and heating. Another study that examined the Philippines was a study by Karasoy (2021) in which they studied how remittances intensified carbon emissions in the Philippines from the period 1977 to 2016 and found that remittances directly contribute to the increase in carbon emissions in the long run while indirectly through oil consumption and income. Included in this study was the estimation of the impact of FDI on the Philippines' environmental degradation. It was explained that in the short run, FDI decreases the country's ecological footprint with the help of cleaner technology transfers and eco-friendly production standards. The study of Karasoy (2021) also involved testing for EKC and how they refuted the validity of this hypothesis as they discovered that the Philippines exhibited a U-shaped curve instead of an inverted U-shaped curve. In their table of results for the ARDL model they employed, a unit increase in GDP per capita decreases ecological footprint while a unit increase in the squared GDP per capita increases it.

Polloni-Silva et al. (2021) explored the applications of the EKC, pollution halo, and pollution haven hypothesis in São Paulo in Brazil. The authors found that results in these hypotheses were inconclusive upon constructing their literature review. For instance, the literature review conducted on EKC showed varying results wherein in some countries, this hypothesis is evident, while in some, it is not. Also, the varying shape of the EKC was also observed and further supported the claim of this hypothesis not having a firm conclusion among studies. The same way goes for the pollution halo, and pollution hypothesis, wherein both claims in which FDI contributes and does not contribute to $\mathrm{CO} 2$ were found in several studies. Findings of their analyses indicate that in Sao Paulo, Brazil, the EKC is validated as GDP and CO2 present a non-linear relationship and found that after a threshold point, GDP decreases the emission of $\mathrm{CO} 2$. Their findings on FDI, on the other hand, only validate the pollution halo hypothesis as they found that an increase in FDI decreases the carbon emissions in their area of study.

In support of the findings in Polloni-Silva et al. (2021), Husnain et al. (2021) published their study wherein they questioned the hypothesis' reliability as there were inconsistent econometric techniques, environmental indicators, as well as other factors that were used in testing. They stated that although EKC is a popular model in interpreting the environmental concerns of economies, one must not be too assured that the results of their study will actually solve the problems we face today. In their study, some of the reasons as to why EKC attracted criticism from researchers were the following: 1) It is difficult to test the EKC hypothesis due to unavailability and inconsistency of pollution indicator data; 2) Studies on EKC yield different results every time, which makes determining the progress of the theory difficult to track; 3) EKC cannot be treated as a universal law because of the inconclusive results of studies that use the same data for testing; 4) Most data for income is highly skewed, which produces compromised regression results; 5) In some cases, EKC is tested in already-developed countries using the wrong time periods, resulting in unreliable results and conclusions. These criticisms essentially try to point out that studies proving (disproving) the EKC hypothesis cannot be generalized (Vincent, 1997, as cited in Husnain et al., 2021) as differently shaped curves were discovered upon testing the theory, some of which were the original inverted U-shaped curve, the N-shaped curve, a wave, and many more. However, even after discussing the problematic nature of EKC, the authors stated that they could not explain the ever-growing popularity of this hypothesis among econometricians. With this, the authors will not dismiss the importance of giving attention to studies relating

Page | 278 
to this as it is, in fact, testing environmental issues that we are collectively trying to solve. Moreover, Husnain et al. (2021) recommend that policymakers avoid promoting economies to further grow their income solely to curb environmental pollution.

\subsubsection{Synthesis}

The literature review revealed several research gaps that will be considered in the empirical analysis of this study. Firstly, there is a lack of studies that explain the increasing amount of $\mathrm{CO} 2$ emissions in the Philippines. To the best of the researchers' knowledge, very few research papers explored this topic in the Philippine setting. Moreover, it was observed that all of them use carbon emissions to account for environmental degradation. This may be because of the lack of data availability for the Philippines.

Secondly, studies that concentrate on the role of GDP contributing to the emission of CO2 make use of the EKC model wherein they square the value of GDP to find the threshold point wherein GDP's continuous rise will become beneficial to countries as greener and more sustainable policies will be implemented. However, the literature review revealed that studies that test the EKC model have no general consensus. The majority of the studies included in the researchers' review of the related literature included those that have proved EKC is valid in the host countries of their studies; however, some still disproved the hypothesis. Moreover, it is hard to ascertain what the situation of the relationship between GDP and CO2 in the Philippines is given that there are very few studies that cover this country. Most of the studies that tested the nexus between these two variables were China and Pakistan. Nonetheless, it was mostly accepted that GDP indeed contributes to CO2 emissions.

Thirdly, it was generally accepted that urbanization and carbon emissions have a relationship. Although some studies refuted a link, the majority concluded that there is. Urbanization gives way for economies to industrialize, be it through urban population migration or through the development of industries on a much larger scale. Ultimately, these factors contribute to environmental degradation. A highly urbanized economy can produce more commodities, and during this process, these economies emit $\mathrm{CO} 2$ as they make use of carbon-emitting sources such as power generation, transportation, and even human activities such as housing for labourers that migrated to these urban areas. Moreover, as an economy becomes more urbanized--or industrialized--more people are compelled to move to these areas because it has more opportunities that would cater to their needs, such as employment, services, education, and other industries. The downside of this is that urbanized areas get too concentrated with urban population growth and accumulate more and more carbon emissions.

Lastly, the studies exploring the relationship between FDI and CO2 emissions showed the most conclusive results. Despite the fact that some studies favoured the pollution haven hypothesis while some, the pollution halo hypothesis, it was generally accepted that FDI brings pollution because of foreign investment in "dirty" or unsustainable industries. To recall, firms are more likely to invest in countries with cheaper production and labour costs. In the literature review, China, Pakistan, and the Philippines all resulted being affected by the adverse effects of FDI, and that all three are developing countries. This is conforming to the studies conveying that developing countries, particularly those with less strict environmental policies, are the most affected by the CO2 emission brought upon by FDI.

\subsection{Theoretical Framework}

\section{A. Environmental Kuznets Curve}

The Environmental Kuznets Curve (EKC) follows the Kuznets (1995) curve in which they hypothesized that greenhouse gas emissions are expected to increase as economies start to accumulate GDP, indicating environmental decay (Grossman and Krueger, 1991). After reaching a turning point, the CO2 levels are expected to decline, indicating environmental improvement (Figure 5).

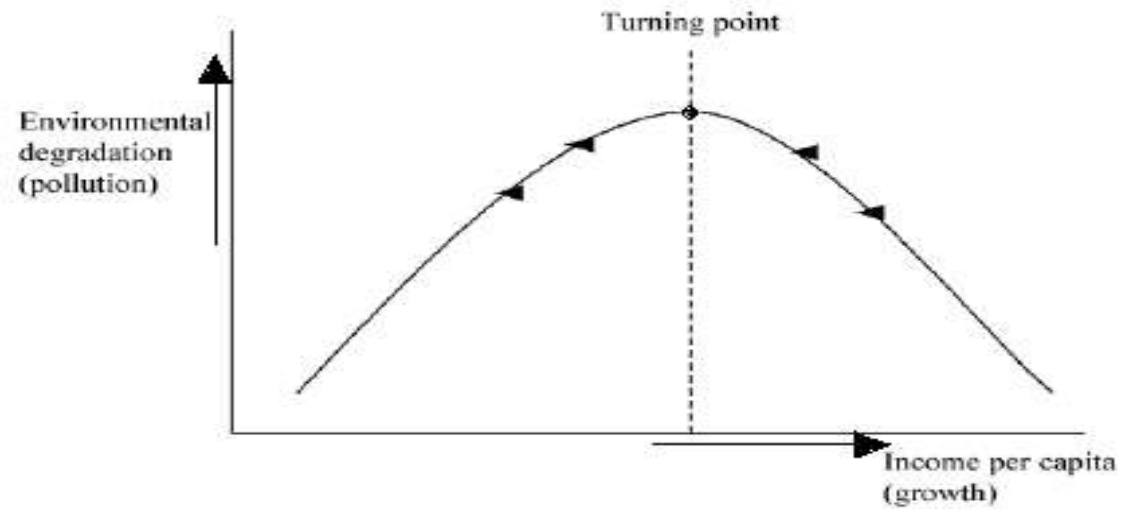

Figure 5. Environmental Kuznets Curve (Grossman and Krueger, 1995) 
Conforming to what has already been established in the literature review, as economies accumulate income, production by industries starts to get more intensive. As time goes by, the more income that comes into the economy, the more it would expand its capacity to establish other industries, particularly towards the high-tech and service industries (Cederborg \& Snöbohm, 2016). One of the classifications in the EKC hypothesis is the scale effect, which describes the initial increase of CO2 emissions in the economy as a result of output increase. It is implied that the right side of the EKC curve is caused by this effect. Underdeveloped and developing economies are usually found to exhibit the scale effect of the curve as they are still just starting out to become industrialized economies; if not, they are already industrialized economies that are still using mechanisms that enhance the intensity of carbon emissions (Cederborg \& Snöbohm, 2016). This is commonly through unsustainable means of production, transportation, and other human economic activities.

While EKC is more commonly used to describe the relationship between $\mathrm{CO} 2$ and economic growth, the researchers of this study will also use this hypothesis to establish the grounds between $\mathrm{CO} 2$ and urbanization. As economies shift to becoming more industrialized, more of the country's population will migrate to these urbanized areas to seek opportunities that would better their economic status. In this study, the researchers used the EKC hypothesis to establish the relationships between economic growth, urbanization, and $\mathrm{CO} 2$ emissions.

\section{B. Pollution Haven Hypothesis}

According to Chatterjee (2019), the pollution haven hypothesis (PHH) is that developed countries with polluting industries impose stricter environmental policies than developing countries, distorting existing patterns of comparative advantage. The PHH also suggests that polluting industries will relocate to jurisdictions with laxer environmental regulations, making them pollution havens. Foreign investors also use developing country lands to produce for their country of origin because their environmental laws and regulations restrict cheap, environmentally harmful technologies. So, while foreign investors gain a significant competitive advantage by producing in countries with lax environmental laws, these developing countries suffer negative environmental consequences as their GDP per capita rises. As it had already been established in the background of the study, the Philippines's foreign investments are mainly concentrated in the manufacturing industries, which are typically highly pollutive. Through the $\mathrm{PHH}$, the researchers of this study can establish the relationship between $\mathrm{CO} 2$ emissions and FDI in the Philippines.

\subsection{Conceptual Framework}

This section of chapter 2 of this thesis illustrates the paper's conceptual framework, wherein it demonstrates the expected result of this study. Following the theoretical framework from the previous section, this study's relevant variables will be substituted to show the flow of this thesis. Upon conducting the literature review and theoretical framework, the researchers of this study conceptualized that carbon emissions are determined by Gross Domestic Product, Foreign Direct Investments, and Urbanization. Figure 6.

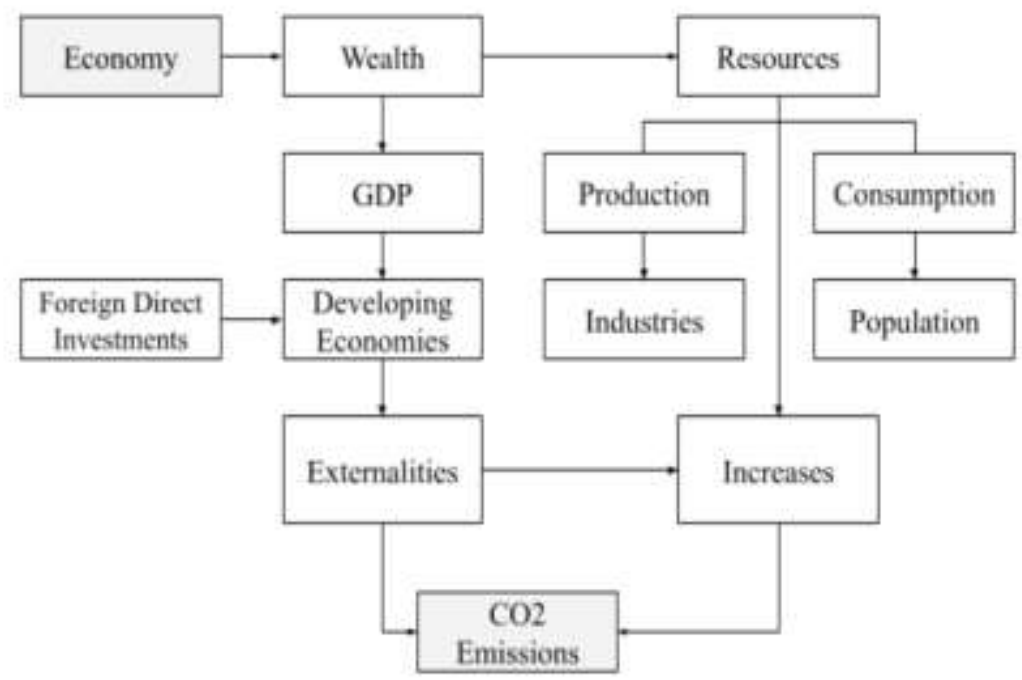

Figure 6. Conceptual Framework of the Thesis

This research paper is denoted by the conceptual framework that $\mathrm{CO} 2$ emissions can be rooted in economic activities. Starting from the top of the framework, an economy's wealth can be measured by its Gross Domestic Product or GDP. This can help determine whether a country is underdeveloped, developing, or developed. In this case, the Philippines is a developing country. 
In line with the EKC hypothesis, CO2 emissions increase as economies start to develop as they tend to produce more commodities through dirty services and industries. This is because the cost of producing commodities is relatively cheaper when using nonrenewable resources as compared to using renewable resources. Moreover, foreign direct investments are expected to flow in when the costs of production in a certain country, with lax environmental laws, are relatively cheaper. This is in line with the pollution haven hypothesis, wherein an inflow of FDI increases CO2 emissions. Lastly, as economies become wealthier, they have the capacity to produce more resources that not only the industries but also the population can use. Urbanization will be expected to increase as different factors can pull people to live in urbanized areas, one of which is access to opportunities brought by economic growth. With that, the urban population will consume as many resources as the economy provides. This, in turn, will produce $\mathrm{CO} 2$ emissions as different human activities, such as transportation and energy consumption, will transpire in these urbanized areas.

\section{Methodology}

\subsection{Research Design}

In conducting this study, the researchers used the quantitative-correlational method in exploring the relationship between carbon emissions, gross domestic product, foreign direct investment, and urbanization. A correlational research design was used as the researchers of this study aimed to determine the relationship between carbon emissions and each of the macroeconomic variables included in this study's model.

\subsection{Data Collection Method}

This study uses time-series data for the Philippines from the period of 1970 to 2018 as there was insufficient data representing the periods before 1970 and after 2018. Data for Carbon Dioxide Emissions in metric tons per capita, Gross Domestic Product in constant 2015 USD, Foreign Direct Investment net inflow as \% of GDP, and Urbanization measured by urban population as \% of the total population were obtained from World Bank Open Data. Table 1 represents the description and units of the variables used in this study.

\subsection{Data Analysis}

The researchers of this thesis will primarily explore how their chosen macroeconomic variables affect the carbon emissions in the Philippines from 1970 to 2018. In line with the literature review, the authors have drawn a general econometric model that can measure the relationship between $\mathrm{CO} 2$ and the different macroeconomic variables. The general model wherein $\mathrm{CO} 2$ is a function of the chosen macroeconomic variables is specified as follows:

$$
C O 2_{t}=f\left(G D P_{t}, F D I_{t}, U R B A N_{t}\right)
$$

In investigating the impact of these factors, the researchers will use ordinary least squares (OLS) multiple regression analysis. OLS multiple regression was chosen to be the primary method in analyzing the dataset as the main objective of this thesis is to assess the impacts of the macroeconomic variables on carbon emissions in the Philippines. With this method, the researchers would be able to assess the significance of the relationships of the variables by looking at the $p$-values of each variable. To investigate the impact of these macroeconomic factors, the researchers have come up with two econometric models representing the variables of this thesis. Below, model 1 is the original econometric model formulated by the authors (Appendix B). Initially, no treatments were done.

$$
C O 2_{t}=\beta_{o}+\beta_{1} G D P_{t}+\beta_{2} F D I_{t}+\beta_{3} U R B A N_{t}+\varepsilon_{t}
$$

Wherein $\beta_{o}$ is the regression coefficient or the $y$-intercept, $\beta_{1}, \beta_{2}$, and $\beta_{3}$ are the parameters for the explanatory variables, which are: GDP as Gross Domestic Product, FDI as Foreign Direct Investments, and URBAN as Urbanization. The researchers initially used other variables found in Chapter 2; however, the econometric models they have formulated around the literature study turned out to be problematic, and that these models violate the CLRM assumptions, specifically multicollinearity and serial correlation. For instance, researchers have heavily used the EKC hypothesis by analyzing the relationship between $\mathrm{CO} 2$ and economic growth (see Chapter 2, Section 2.1.4). This hypothesis uses GDP per capita as well as its squared value in the econometric model. After several trials and errors and a number of diagnostic tests, the researchers found that when estimating carbon emission with GDP per capita and GDP per capita squared both as regressors; multicollinearity is bound to happen. Although this does not produce a perfectly collinear relationship, GDP per capita and GDP per capita squared being bound to be collinear makes the OLS regression biased and unreliable results. Thus, the researchers of this study omitted the problematic variables, which enabled them to accurately estimate the impacts of the independent variables on the dependent variable of this study.

$C O 2_{t}=\beta_{o}+\beta_{1} G D P_{t}+\beta_{2} F D I_{t}+\beta_{3} U R B A N_{t}+\beta_{4} C O 2_{t-1}+\varepsilon_{t}$ 
Another econometric model has been formulated, which can be seen above (Model 2). The authors employed a lagged dependent variable which can be used to resolve the problem of autocorrelation, which will be demonstrated in Chapter 4 . The second model uses the same variables as the first one, but with the addition of a lagged value, which is CO2(-1).

\subsection{Statistical Treatment}

The researchers of this study used secondary data gathered from the World Bank Economic Indicators. In order to interpret the data and produce statistically accurate results, statistical treatments must be considered. Moreover, the statistical treatments that will be discussed should ensure that this study does not violate the classical linear regression model (CLRM)'s assumptions. These statistical tests will be employed using Eviews 11 Student Version. The following statistical treatments will be used in interpreting the econometric model:

The Goodness of Fit test. This test should determine how much an econometric model fits in the observations that will be analyzed (Maydeu-Olivares \& Forero, 2010). To determine the model's goodness of fit, one must look at the R-squared of the regression results. According to Gujarati (2004), the goodness of fit test can be used to analyze questionable R squared values.

The Jarque-Bera test. This will test the normality of the data (Gujarati, 2004). Specifically, it tests the skewness or the measure of the data's symmetry. The null hypothesis when using the Jarque-Bera test is that the error terms are normally distributed. The goal is to accept the null hypothesis, wherein the Jarque Bera Probability is more than 0.05 .

Breusch-Pagan-Godfrey Test. Heteroskedasticity is a problem encountered in econometric models wherein there is no equal variance in the error term in all observations to be used in the empirical analyses. In order to test whether there is a presence of heteroskedasticity in the model, the Breusch-Pagan-Godfrey test will be used. The p-value must be greater than 0.05 in order to fail to reject the null hypothesis of homoscedasticity. This means that the error term displays equal variance for all observations (Gujarati, 2004).

1)

Breusch-Pagan Serial Correlation LM Test. The problem of autocorrelation may be encountered upon analyzing the data; therefore, it is important to include a test to detect this violation of the CLRM assumption. Serial correlation occurs when the error terms of the econometric model exhibit correlation (Gujarati, 2004).

Variance Inflation Factor (VIF) Test. Multicollinearity is another problem the researchers might encounter during data analysis. It is another violation of the CLRM assumptions; wherein there should be no perfect or exact linear relationship among the explanatory variables (Gujarati, 2004). Moreover, multicollinearity is said to make the explanatory variables unstable and to increase their variance. Therefore, the researchers find it most appropriate to use VIF in determining whether there is multicollinearity present in the data. A general rule of thumb is for the VIF not to exceed 10, however there Shrestha (2020) states that when the VIF is more than 5 to 10 , then multicollinearity is present in the variables.

Ramsey RESET test. In order to test the model for specification error, this test will be employed. A misspecified model introduces bias, and it indicates that the econometric model uses the wrong functional form (Gujarati, 2004). By utilizing the Ramsey RESET test, the researchers will know whether or not the addition and the omission of variables make their econometric model correctly specified and meet the CLRM assumption that the model must not demonstrate any specification errors.

\section{Results and discussion}

\subsection{Regression Results}

It was found that the initial model suffers from serial correlation and heteroskedasticity. As a remedy, the researcher employed their second proposed model. The lagged dependent variable, CO2(-1), was added to the econometric equation to solve the problem of serial correlation. Table 1 represents the adjusted model wherein some changes have been observed, particularly in the regression table, Durbin-Watson statistic, VIF scores, as well as the results of the Breusch-Pagan-Godfrey and Breusch-Godfrey Serial Correlation LM tests. 
Regression Table

\begin{tabular}{lllll} 
Variable & Coefficient & Standard Errors & t-Statistic & Prob. \\
\hline C & $\mathbf{0 . 0 9 0 3 8 6}$ & 0.092108 & 0.981301 & $\mathbf{0 . 3 3 1 9}$ \\
\hline GDP & $\mathbf{0 . 0 0 0 0 5 7}$ & 0.000023 & 2.501979 & $\mathbf{0 . 0 1 6 2}$ \\
\hline FDI & $\mathbf{0 . 0 3 0 6 0 0}$ & 0.011267 & 2.716002 & $\mathbf{0 . 0 0 8 5}$ \\
\hline URBAN & $\mathbf{- 0 . 0 0 2 2 1 9}$ & 0.002106 & -1.053504 & $\mathbf{0 . 2 9 8 0}$ \\
\hline CO2(-1) & $\mathbf{0 . 8 3 7 4 0 6}$ & 0.072482 & 11.55329 & $\mathbf{0 . 0 0 0 0}$ \\
& & & & \\
& R-squared & $\mathbf{0 . 9 3 4 7 5 2}$ & & \\
& F-statistic & 154.0067 & &
\end{tabular}

Adjusted R-squared

Prob(F-Statistic)

Durbin-Watson Statistic

Jarque-Bera Probability Test
0.928683

0.000000

1.762834

0.360008

Variance Inflation Factor (VIF) Test

\begin{tabular}{|c|c|c|c|}
\hline Variable & Coefficient Variance & Uncentered VIF & Centred \\
\hline $\mathrm{C}$ & 0.008484 & 179.6899 & NA \\
\hline GDP & 0.000000 & 47.64786 & 2.65789 \\
\hline FDI & 0.000127 & 6.150731 & 2.11266 \\
\hline URBAN & 0.000004 & 177.3395 & 1.79881 \\
\hline \multirow[t]{3}{*}{$\operatorname{co} 2(-1)$} & 0.005254 & 78.41267 & 2.91929 \\
\hline & \multirow{2}{*}{$\begin{array}{l}\text { Breusch-Pagan-Godfrey Tes } \\
\text { Breusch-Godfrey LM Test }\end{array}$} & \multicolumn{2}{|l|}{0.6804} \\
\hline & & \multicolumn{2}{|l|}{0.4569} \\
\hline \multicolumn{4}{|c|}{ Ramsey RESET Test } \\
\hline & Value & df & Prob. \\
\hline t-statistic & 0.456601 & 42 & 0.6503 \\
\hline F-statistic & 0.208485 & $(1,41)$ & 0.6503 \\
\hline Likelihood ratio & 0.237679 & 1 & 0.6259 \\
\hline
\end{tabular}

Table 1. Adjusted Model Results 
First and foremost, the R-squared value is 0.934752 , which means that $93.48 \%$ of the variables fit the model. Additionally, the authors needed to determine if the model uses normally distributed data that can be checked using the Jarque-Bera Normality test. The test resulted in a p-value of 0.360008 , which means that the residuals of this model are normally distributed as it exceeds the $p$-value of 0.05 required to satisfy this assumption.

Next, the Durbin-Watson statistic in Table 1 has a value of 1.762834, indicating no more serial correlation present in the model. This is further supported by the results of the Breusch-Godfrey Serial Correlation LM test, which showed a p-value of 0.4569, demonstrating that there is no serial correlation in the model. This complies with the CLRM assumptions wherein there must be no serial correlation between the disturbance in the model (Gujarati, 2004).

After that, the authors checked for collinearity between variables using the VIF test, in which the results reveal that there is no perfect linear relationship between the dependent variable and the independent variables in this model. As observed in Table 1, the centred VIF score of GDP is 2.657899 , FDI is 2.112667, URBAN is 1.798815 , and CO2(-1) is 2.919298. To reiterate what has already been stated in Chapter 3, if the VIF score is less than 10, that indicates there is no linear combination of the dependent and independent variables, or what is commonly called multicollinearity, found in the model.

The Breusch-Pagan-Godfrey Test is then employed to determine whether or not the model still exhibits homoskedasticity. The $\mathrm{p}$ value of 0.6804 implies that the model is now homoskedastic. This means that the disturbance errors in the model display equal spread. After testing if the adjusted model has been effectively treated, the Ramsey RESET test was employed to determine whether or not there are specification errors found in the model. As seen in Table 1, the p-values show that there is no specification error in the model as the $\mathrm{p}$-values exceed 0.05 . This means that the econometric model used in this study is correctly specified.

Finally, as seen in Table 1, GDP, FDI, and CO2(-1) are statistically significant with p-values below 0.05 . The results imply that a unit increase in GDP increases CO2 by 0.000057; a unit increase in FDI increases CO2 by 0.030600; a unit increase in URBAN decreases CO2 by 0.002219 ; and a unit increase in CO2(-1) increases CO2 by 0.837406 . However, the p-value of URBAN is 0.2980 , which is statistically insignificant, meaning that the coefficient of URBAN cannot be concluded if it really decreases CO2 by that number of units.

\subsection{Discussion}

Based on the previously presented results, this study's researchers will not discuss the implications of the results in line with the study's literature review findings. This study finds that both Gross Domestic Product and Foreign Direct Investment contribute to $\mathrm{CO} 2$ emissions in the Philippines. Moreover, the lagged dependent variable shows that $\mathrm{CO} 2$ emissions would increase in the next period by .83 units. This essentially means that $\mathrm{CO} 2$ will continuously increase as the Philippine economy moves forward.

The study shows that gross domestic product positively impacts $\mathrm{CO} 2$ emissions. This finding conforms with the idea presented in the EKC hypothesis's scale effect wherein an economy's increase in income has adverse effects on the environment. To interpret the results, the findings are comparable to that of Buenavista and Palanca-Tan (2021), wherein they explained how environmental degradation is accelerated by GDP due to the increase in the production of commodities in the economy. As established in the background of the study, the Philippines' economic growth is driven by industries that are reliant on non-renewable energy sources, particularly fossil fuels. The dominating shares of the construction, manufacturing, and the rest of the industries that may fall under "dirty industries" undoubtedly boost the country's total output. However, through the researchers' empirical analysis, it has been proven that this increase in GDP gradually destroys the environment as well. This indicates that the government must come up with environmental laws that are stricter in relation to CO2 emissions. Currently, the Philippines only has five major environmental laws established by the Environmental Management Bureau (EMB), which are: 1) Republic Act 9003 Ecological Solid Waste Management Act Of 2000, 2) Republic Act 9275 Philippine Clean Water Act Of 2004, 3) Republic Act 8749 Philippine Clean Air Act Of 1999, 4) Republic Act 6969 Toxic Substances, Hazardous And Nuclear Waste Control Act Of 1990, and the 5) Presidential Decree 1586 Environmental Impact Statement (Eis) Statement Of 1978. The third mentioned major law is relevant to this study as was examined by the researchers. It was found that although the Philippines had a law that is supposed to protect its air quality, it is often being brushed aside. The Clean Air Act of 1999 is continuously being weakened as CO2 emissions, among the other classified pollutants in its provisions, steadily get worse through the years (Figure 1).

Foreign Direct Investment also exhibits a positive impact on $\mathrm{CO} 2$ emissions in the Philippines. This conforms to the Pollution Haven Hypothesis. This may be explained by the Philippines as a developing country, making it a potential investment for other countries and the sectoral distribution of FDI in the country, which has been introduced in the background of the study. In accordance with Palanca-Tan \& Tan. (2016), indeed, the manufacturing sector of the Philippines accounts for the majority of the FDI shares. This is further supported by the study of Kim (2019), wherein he reiterates that countries with no strict laws on CO2 emissions demonstrate vulnerability to the adverse effects FDI brings. In line with this, the passing of the R.A. No. 8179 has allowed more foreign

Page | 284 
investments to come in the Philippines, allowing foreign equity participation up to a hundred percent except in areas stated in the Foreign Investment Negative List (FINL) or those that are exclusively for Filipinos (Austria, 1998). Moreover, investors are given incentives when they choose to invest in the country, such as those under the Omnibus Investment Code of 1987, Special Economic Zone Act of 1995, and the Bases Conversion and Development Act of 1992 (Embassy of the Republic of the Philippines, 2021). Under this R.A. No. 8179, all foreign investors are subject to existing environmental policies in the Philippines. However, despite having implemented environmental laws, like the Clean Air Act of 1999 in particular, the trend of CO2 emissions still remains upward until 2018. This puts the Philippines in a predicament in which it found itself not improving the environmental quality of the Philippines despite implementing laws that are supposed to curb environmental degradation. This suggests that the Philippines' existing environmental law is inadequate to protect it from the consequences of various economic activities. This only allows industries and foreign investors to exploit the resources in the Philippines without necessarily having to comply with the strict regulations imposed by the law.

Lastly, the results of this study revealed that urbanization in the econometric model used had an insignificant relationship with $\mathrm{CO} 2$ emissions. Thus, the researchers fail to reject the null hypothesis. However, it is important to note that the researchers cannot accept the null hypothesis that urbanization does not contribute to $\mathrm{CO} 2$ emissions in the Philippines. In reality, there is no sufficient evidence that urbanization has zero or no effect on $\mathrm{CO} 2$ emissions; therefore, the researchers cannot conclude whether it has an effect or that it does not.

\section{Conclusion and Recommendations}

The aim of this study is to analyze the impacts of three macroeconomic variables, namely, Gross Domestic Product, Foreign Direct Investment, and Urban Population, on the emissions of CO2 in the Philippines from the period of 1970 to 2018. This study uses the Ordinary Least Squares multiple regression model and found that both Gross Domestic Product and Foreign Direct Investments influence $\mathrm{CO} 2$ emissions. The findings of this study support the scale effect presented in the Environmental Kuznets Curve and the Pollution Haven Hypothesis. The researchers would recommend policymakers be more strict with the existing and future environmental laws they wish to implement.

The researchers of this study recognized that this paper does not cover all issues related to the study of $\mathrm{CO} 2$ emissions and Economic Growth. To further improve this study, the authors recommend future researchers test the applicability of the Environmental Kuznets Curve Hypothesis in their studies in order to determine whether the Philippines is already near the turning point wherein there will be environmental recovery. Moreover, the researchers suggest that a larger sample size for urbanization should be used in future research in order to test if the results are still statistically insignificant. Lastly, other variables may be added to the model, such as energy consumption, trade openness, and others that may be encountered upon conducting a literature review.

Funding: This research received no external funding.

Conflicts of Interest: The authors declare no conflict of interest.

\section{References}

[1] Adu, D.T. \& Denkriyah, E.K. (2017). Economic Growth and Environmental Pollution in West Africa: Testing the Environmental Kuznets Curve hypothesis. Kasetsart Journal of Social Sciences, 40, 281-288. https://doi.org/10.1016/j.kjss.2017.12.008

[2] Ahmed, Z., Ali, S. Saud, S., \& Shahzad, S.J.H. (2020). Transport CO2 emissions, drivers, and mitigation: An Empirical Investigation in India. Air Quality, Atmosphere \& Health, 13, 1367-1374. https://doi.org/10.1007/s11869-020-00891-x

[3] Ahmed, Z. Asghar, M. M., Malik, M. N., \& Nawaz, K. (2020). Moving Towards A Sustainable Environment: The Dynamic Linkage Between Natural Resources, Human Capital, Urbanization, Economic Growth, and Ecological Footprint in China. Resources Policy, 67.https://10.1016/j.resourpol.2020.101677

[4] Ali, R., Bakhsh, K., \& Yasin, M.A. (2019). Impact of urbanization on CO2 emissions in an emerging economy: Evidence from Pakistan. Sustainable Cities and Society, 48. https://doi.org/10.1016/j.scs.2019.101553

[5] Austria, M.S. (1998). The Emerging Philippine Investment Environment. PIDS Discussion Paper Series, Philippine Institute for Development Studies. https://www.econstor.eu/handle/10419/187369

[6] Bakhsh, K., Rose, S., Ali, M.F., Ahmad, N., \& Shahbaz, M. (2017). Economic growth, CO2 emissions, renewable waste and FDI relation in Pakistan: New evidence from 3SLS. Journal of Environmental Management, 1196, 627-632. https://doi.org/10.1016/j.jenvman.2017.03.029

[7] Beyene, S. D. \& Kotosz, B. (2019). Testing the environmental Kuznets curve hypothesis: an empirical study for East African countries. International Journal of Environmental Studies, 77(4), 636-654. https://doi.org/10.1080/00207233.2019.1695445

[8] Buenavista, M.J.M. \& Palanca-Tan, R. (2021). Carbon Dioxide Emissions and the Macroeconomy: Evidence from the ASEAN Region. Philippine Journal of Science, 150(3), 737-745. https://philjournalsci.dost.gov.ph/105-vol-150-no-3-june-2021/1382-carbon-dioxideemissions-and-the-macroeconomy-evidence-from-the-asean-region

[9] Cai, L., Firdousi, S.F., Li, C., \& Luo, Y. (2021). Inward foreign direct investment, outward foreign direct investment, and carbon dioxide emission intensity-threshold regression analysis based on interprovincial panel data. Environmental Science and Pollution Research, 28(34), 46147-46160. https://doi.org/10.1007/s11356-020-11909-3 
[10] Carlowicz, M. (2013). Super Typhoon Haiyan Surges Across the Philippines. NASA Earth Observatory. https://earthobservatory.nasa.gov/images/82348/super-typhoon-haiyan-surges-across-the-philippines

[11] Cederborg, J. \& Snöbohm, S. (2016). Is there a relationship between economic growth and carbon dioxide emissions?. Södertörns University, Institution of Social Sciences. https://www.diva-portal.org/smash/get/diva2:1076315/FULLTEXT01.pdf

[12] Commission on Human Rights Philippines. (2018). CHR to conduct the first hearing investigating the possible contribution of carbon to climate change and its impact on human rights. http://chr.gov.ph/chr-to-conduct-first-hearing-investigating-possible-contribution-ofcarbon-to-climate-change-and-its-impact-on-human-rights/

[13] Chatterjee, T. (2019). Environmental Regulation, International Trade, and Informal Sector: Theory, Policy, and Indian Experience. In Handbook of Research on Economic and Political Implications of Green Trading and Energy Use. IGI Global. DOI: 10.4018/978-1-5225-8547-3.ch005

[14] Chishti, M.Z., Ahmed, Z., Murshed, M., Namkambe, H.H., \& Ulucak, R. (2021). The asymmetric associations between foreign direct investment inflows, terrorism, $\mathrm{CO} 2$ emissions, and economic growth: a tale of two shocks. Environmental Science and Pollution Research. https://doi.org/10.1007/s11356-021-15188-4

[15] Climate Transparency Organization. (2020). Philippines, Country Profile 2020. https://www.climate-transparency.org/media/philippinescountry-profile-2020

[16] Department of Energy. (2020). Energy Outlook 2020. https://www.doe.gov.ph/sites/default/files/pdf/announcements/2 Energy\%20Oulook 19\%20Aug\%202020.pdf

[17] Department of Trade and Industry. (2018). Foreign investments in the manufacturing sector soared $244 \%$ in 2017 . Securing The Future of Philippine Industries. https://industry.gov.ph/foreign-investments-in-manufacturing-sector-soared-244-in-2017/

[18] Embassy of the Republic of the Philippines. (2021). What are possible incentive schemes available for an investor?. Frequently Asked Questions (FAQs). https://www.philippine-embassy.org.sg/doing-business/frequently-asked-questions-faqs/

[19] Environmental Management Bureau. (n.d.). Major Environmental Laws. https://ecac.emb.gov.ph/?page id=43

[20] Fernandez, H.A. (2021). The Philippines cannot do without fossil fuels just yet: Ayala And Lopez bosses. Eco-business. https://www.ecobusiness.com/news/the-philippines-cannot-do-without-fossil-fuels-just-yet-ayala-and-lopez-bosses/?sw-signup=true

[21] Gill, A. R., Viswanathan, K. K., \& Hassan, S. (2018). The Environmental Kuznets Curve (EKC) and the environmental problem of the day. Renewable and Sustainable Energy Reviews, 81(2), 1636-1642. https://doi.org/10.1016/j.rser.2017.05.247

[22] Grossman, G.M. \& Krueger, A.B. (1991). Environmental Impacts of the North American Trade Agreement. NATIONAL BUREAU OF ECONOMIC RESEARCH. https://doi.org/10.3386/w3914

[23] Gujarati, D.N. (2004). Basic Econometrics. Boston, Mass: McGraw-Hill.

[24] Husnain, M.I.U., Haider, A. \& Khan, M.A. (2021). Does the environmental Kuznets curve reliably explain a developmental issue? Environmental Science and Pollution Research, 28(9), 11469-11485. https://doi.org/10.1007/s11356-020-11402-x

[25] Ibanez, J., Pedrasa, M.A., \& Magadia, J. (2019). Relationship of Economic Growth and Co2 Emissions in the Philippines: An EKC Hypothesis Testing Case Study. 2019 9th International Conference on Power and Energy Systems (ICPES). https://doi.org/10.1109/ICPES47639.2019.9105362

[26] Karasoy, A. (2021). How do remittances to the Philippines affect its environmental sustainability? Evidence-based on the augmented ARDL approach. Natural Resources Forum A United Nations Sustainable Development Journal, 45(2), 120-137. https://doi.org/10.1111/1477$\underline{8947.12218}$

[27] Kim, S. (2019). CO2 Emissions, Foreign Direct Investments, Energy Consumption, and GDP in Developing Countries: A More Comprehensive Study using Panel Vector Error Correction Model. Korean Economic Review, 35, 5-24. http://keapaper.kea.ne.kr/RePEc/kea/keappr/KER20190101-35-1-01.pdf

[28] Kusumawardani, D. \& Dewi, A.K. (2020). The effect of income inequality on carbon dioxide emissions: A case study of Indonesia. Heliyon, 6(8). https://doi.org/10.1016/j.heliyon.2020.e04772

[29] Liu, Q., Wang, S., Zhang, W., Li, J., \& Kong, Y. (2019). Examining the effects of income inequality on CO2 emissions: Evidence from nonspatial and spatial perspectives. Applied Energy, 236, 163-171. https://doi.org/10.1016/j.apenergy.2018.11.082

[30] O'Sullivan, A., Sheffrin, S.M., \& Perez, S.J. (2012). Economics Principles, Applications, and Tools (7th Edition). Pearson Education Ltd.

[31] Palanca-Tan, R. Dy, T.A., \& Tan, A. (2016). Relating Carbon Dioxide Emissions with Macroeconomic Variables in the Philippine Setting. Low Carbon Economy, 7(1), 12-20. https://doi.org/10.4236/lce.2016.71002

[32] Polloni-Silva, E., Ferraz, D., De Castro Camioto, F., Do Nascimento Rebelatto, D.A., \& Moralles, H.F. (2021). Environmental Kuznets Curve and the Pollution-Halo/Haven Hypotheses: An Investigation in Brazilian Municipalities. Sustainability 2021, 13(8), 4114; https://doi.org/10.3390/su13084114

[33] Philippine Atmospheric, Geophysical and Astronomical Services Administration. (n.d.). Climate Change in the Philippines. https://www.pagasa.dost.gov.ph/information/climate-change-in-the-philippines

[34] Philippine Board of Investments. (2017). THE PHILIPPINE MANUFACTURING INDUSTRY PROFILE. Manufacturing. https://boi.gov.ph/sdm downloads/manufacturing-2/

[35] Philippine Statistics Authority. (2019). Employment Situation in January 2019. https://psa.gov.ph/statistics/survey/labor-andemployment/labor-force-survey/title/Employment\%20Situation\%20in\%20January\%202019

[36] Philippine Statistics Authority. (2018). Foreign Investments Fourth Quarter 2018. The Foreign Investments in the Philippines. https://psa.gov.ph/sites/default/files/FI\%20Report\%20Q4\%202018.pdf

[37] Philippine Statistics Authority. (2019). Philippine GDP grew 6.1 percent in the fourth quarter of 2018; 6.2 percent in 2018. https://psa.gov.ph/content/philippine-gdp-grows-61-percent-fourth-quarter-2018-62-percent-2018

[38] Philippine Statistics Authority. (2019). Urban Population in the Philippines (Results of the 2015 Census of Population). https://psa.gov.ph/content/urban-population-philippines-results-2015-census-population

[39] Mahadevan, R. \& Sun, Y. (2019). Effects of foreign direct investment on carbon emissions: Evidence from China and its Belt and Road countries. Journal of Environmental Management, 276. https://doi.org/10.1016/j.jenvman.2020.111321 
[40] Malik, M.Y., Latif, K., Khan, Z., Butt, H.D., Hussain, M., \& Nadeem, M.A. (2020). Symmetric and asymmetric impact of oil price, FDI and economic growth on carbon emission in Pakistan: Evidence from ARDL and non-linear ARDL approach. Science of The Total Environment, 726. https://doi.org/10.1016/j.scitotenv.2020.138421

[41] Maneejuk, N., Ratchakom, S., Maneejukm, P., \& Yamaka, W. (2020). Does the Environmental Kuznets Curve Exist? An International Study. Sustainability 2020, 12(21). https://doi.org/10.3390/su12219117

[42] Månsson, K., Kibria, B.M.G., Shukur, G., \& Sjölander, P. (2018). On the Estimation of the CO2 Emission, Economic Growth and Energy Consumption Nexus Using Dynamic OLS in the Presence of Multicollinearity. Sustainability 2018, 10(5). https://doi.org/10.3390/su10051315

[43] Maydeu-Olivares, A. \& Forero, C.G. (2010). Goodness-of-Fit Testing. Retrieved from https://www.researchgate.net/publication/283839108 Goodness-of-Fit Testing

[44] Mercado-Aldaba, R.A. (1994). Foreign Direct Investment in the Philippines: A Reassessment. Philippine Institute for Development Studies. https://ideas.repec.org/p/phd/rpseri/rps 1994-10.html

[45] Mersereau, D. (2013). Why did so many people die from Haiyan and past southeast Asia typhoons? The Washington Post. https://www.washingtonpost.com/news/capital-weather-gang/wp/2013/11/11/inside-the-staggering-death-toll-from-haiyan-and-othersoutheast-asia-typhoons/

[46] Mignamissi, D. \& Djeufack, A. (2021). Urbanization and CO2 emissions intensity in Africa. Journal of Environmental Planning and Management. https://doi.org/10.1080/09640568.2021.1943329

[47] National Inquiry On Climate Change. (2018). Commission on Human Rights of the Philippines' National Inquiry on Climate Change [Video file]. YouTube. https://www.youtube.com/watch?v=vSetBd6lo8s\&t=2083s

[48] Rafindadi, A.A., Muye, I.M., \& Kaita, R.A. (2018). The effects of FDI and energy consumption on environmental pollution in predominantly resource-based economies of the GCC. Sustainable Energy Technologies and Assessments, 25, 126-137. https://doi.org/10.1016/j.seta.2017.12.008

[49] Rani, R. \& Kumar, N. (2019). Investigating the Presence of Environmental Kuznets Curve Hypothesis in India and China: An Autoregressive Distributive Lag Approach. Jindal Journal of Business Research, 8(2), 194-210. https://doi.org/10.1177/2278682119880510

[50] Ridzuan, A.R, Sapuan, N.M.,Rahman, N.H.A., Borhan, H., \& Othman, A. (2019). The Impact Of Corruption On Environmental Quality In The Developing Countries Of Asean-3: The Application Of The Bound Test. International Journal of Energy Economics and Policy, 9(6). https://doi.org/10.32479/ijeep.8135

[51] Rincón, M. F.,Virtucio, F. (2008). Climate Change in the Philippines: A Contribution to the Country Environmental Analysis https://aboutphilippines.org/documents-etc/Climate-Change-in-the-Philippines.pdf

[52] Shrestha, N. (2020). Detecting Multicollinearity in Regression Analysis. American Journal of Applied Mathematics and Statistics, 8(2), 39-42. https://doi.org/10.12691/ajams-8-2-1

[53] Sun, H., Samuel, C.A., Amissah, J.C.K., Taghizadeh-Hesary, F., \& Mensah, I.A. (2020). Non-linear nexus between CO2 emissions and economic growth: A comparison of OECD and B\&R countries. Energy, 212. https://doi.org/10.1016/j.energy.2020.118637

[54] Tan, S-H., Hong, M., \& Chan, T-H. (2020). Economic Growth, Urbanization and Carbon Emissions: Evidence from Selected ASEAN Countries. International Journal of Industrial Management, 6(1), 9-6. https://doi.org/10.15282/ijim.6.0.2020.5637

[55] UN-Habitat. (2015). Philippines [Brochure]. Achieving Sustainable Urban Development. http://unhabitat.org.ph/wpcontent/uploads/2015/12/Brochure-ASUD-Project-Brief-A4-Singles.pdf

[56] Vincent, J.R. (1997). Testing for environmental kuznets curves within a developing country. Environment and Development Economics, 2(4), 417-431. https://doi.org/10.1017/s1355770x97000223

[57] Wang, Q., Wang, X., \& Li, R. (2021). Does urbanization redefine the environmental Kuznets curve? An empirical analysis of 134 Countries. Sustainable Cities and Society, 76. https://doi.org/10.1016/j.scs.2021.103382

[58] World Bank. (2017). PHILIPPINES URBANIZATION REVIEW - FOSTERING COMPETITIVE, SUSTAINABLE AND INCLUSIVE CITIES. https://documents1.worldbank.org/curated/en/963061495807736752/pdf/114088-REVISED-PUBLIC-Philippines-Urbanization-Review-FullReport.pdf

[59] Xu, Q., YuXiang, D., \& Ren, Y. (2018). Urbanization impact on carbon emissions in the Pearl River Delta region: Kuznets curve relationships. Journal of Cleaner Production, 180, 514-523. https://doi.org/10.1016/i.jclepro.2018.01.194

[60] Zhang, S., Li, Z., Ning, X., \& Li, L. (2021). Gauging the impacts of urbanization on CO2 emissions from the construction industry: Evidence from China. Journal of Environmental Management, 288. https://doi.org/10.1016/j.jenvman.2021.112440

[61] Zhang, C. \& Zhou, X. (2016). Does foreign direct investment lead to lower CO2 emissions? Evidence from a regional analysis in China. Renewable and Sustainable Energy Reviews, 58, 943-951. https://doi.org/10.1016/j.rser.2015.12.226 